\title{
Use of Radio-Telemetry to Test for Investigator Effects on Nesting Mallards, Anas platyrhynchos
}

\author{
Terri D. Thorn ${ }^{1}$, Robert B. Emery ${ }^{2}$, David W. Howerter, JAmes H. Devries, and Brian L. Joynt \\ Institute for Wetland and Waterfowl Research, Ducks Unlimited Canada, P.O. Box 1160, Stonewall, Manitoba R0C 2Z0 \\ Canada \\ ${ }^{1}$ Current Address: U.S. Fish and Wildlife Service, 3425 Miriam Ave., Bismarck, North Dakota 58501-7926 USA \\ ${ }^{2}$ Corresponding author: e-mail: b_emery@ducks.ca
}

Thorn, Terri D., Robert B. Emery, David W. Howerter, James H. Devries, and Brian L. Joynt. 2005. Use of radio-telemetry to test for investigator effects on nesting Mallards, Anas platyrhynchos. Canadian Field-Naturalist 119(4): 541-545.

We examined the effects of investigator activity on hatching rates of radio-marked wild female Mallards (Anas platyrhynchos), and evaluated the efficacy of radio-telemetry to minimize nest disturbance, characterize vegetation at nest sites, and mark nests for later relocation. Differences in hatching rates between birds that were flushed once (experimental) and those never flushed (control) approached significance $(P=0.086)$. However, hatching rates did not differ $(P=0.588)$ between the two groups when nests where investigator activity caused abandonment (30\% of experimental nests) were removed from analysis. If the nest remained active, flushing the bird and visiting the nest once did not appear to increase the likelihood of the nest being depredated. We were able to locate $92 \%$ of radio-telemetry marked nests (control) after the female was no longer tending the nest. Radio-telemetry provides a technique to collect relatively unbiased nesting data for Mallards without disturbing the female.

Key Words: Mallard, Anas platyrhynchos, nests, hatching-rates, investigator effects, abandonment, radio-telemetry.

Investigating reproductive performance of waterfowl often requires physically locating nests followed by repeat visits until the nest's fate is determined. However, locating and revisiting nesting birds may influence reproductive performance by causing nest abandonment and by subsequently affecting renesting. Also, investigator visits to the nest may aid predators in locating and destroying nests and thus result in biased estimates of nest survival. Alternatively, predators may avoid human scent, leading to increased nest survival.

Potential negative influences of investigator activity on estimates of reproductive success have been recognized for decades in waterfowl research (Bennett 1938; Low 1940; Hammond and Forward 1956). Unfortunately, results of studies of investigator impact on waterfowl hatching rates have been equivocal. Earl (1950) and Hammond and Forward (1956), suggested that investigator presence lowered nesting success, whereas Gotmark and Ahlund (1984), Livezey (1980), and Sedinger (1990) did not find this to be true. In contrast, observer activity may increase nest abandonment (Balat 1969; Reed 1975; Livezey 1980).

Various methods (see Gotmark 1992 for review) have been used to test for investigator influences on reproductive parameters. However, locating and monitoring same-aged, undisturbed, natural duck nests (control) has been difficult. This can be crucial when trying to estimate accurately investigator-caused influences on hatching rates. Artificial nests have been used to facilitate such comparisons (e.g., Gottfried and Thompson 1978; Vacca and Handel 1988; Sullivan and Dinsmore 1990). Extrapolating estimates from artificial nests to natural nests might not be entirely valid, because artificial nests are "visited" when deployed (Gotmark et al. 1990; MacIvor et al. 1990; Hendricks and Reinking 1994; but see Olson and Rohwer 1998), and artificial nests may be poor substitutes for estimating hatching rates of natural nests (see Butler and Rotella 1998). Radio-telemetry offers a partial alternative by allowing remote monitoring of nesting waterfowl.

We used radio-telemetry to monitor duck reproductive performance in response to upland habitat manipulation during the Prairie Habitat Joint Venture (PHJV) assessment program of the North American Waterfowl Management Plan. Original PHJV assessment program protocols stated that if a female was suspected of having a nest, she was flushed to determine nest site location. We designed a study to determine whether flushing females and visiting a nest once reduced hatching rates. Specifically, our objectives were to: (1) determine the impact on hatching rates of flushing a female Mallard (Anas platyrhynchos) and visiting her nest early in the nesting cycle, (2) if there was an impact, determine its cause, and (3) evaluate the efficacy of our radio-telemetry nest-marking protocols.

\section{Study Areas and Methods}

Data were collected from three $64.75-\mathrm{km}^{2}$ areas in the prairie pothole region of Canada (Bellrose 1980; Poston et al. 1990). Study areas were centred approximately $1 \mathrm{~km}$ west of Belmont, Manitoba $\left(49^{\circ} 25^{\prime} \mathrm{N}\right.$, $\left.99^{\circ} 29^{\prime} \mathrm{W}\right), 5 \mathrm{~km}$ northeast of Davis, Saskatchewan $\left(53^{\circ} 9^{\prime} \mathrm{N}, 105^{\circ} 37^{\prime} \mathrm{W}\right)$, and approximately $3 \mathrm{~km}$ west of Erskine, Alberta $\left(52^{\circ} 19^{\prime} \mathrm{N}, 112^{\circ} 55^{\prime} \mathrm{W}\right)$. These landscapes, 
characterized by flat to rolling topography, have been altered by cultivation for cereal and oil-seed crops, forage production, and livestock grazing.

We decoy-trapped (Sharp and Lokemoen 1987; Ringelman 1990) 135, 136 and 135 pre-laying female Mallards at Belmont, Davis and Erskine, respectively, during 6 - 28 April 1994. Females either were implanted with a radio transmitter (Olsen et al. 1992; all females at Belmont and Davis and 67 females at Erskine) or transmitters were anchor/sutured to their backs (Mauser and Jarvis 1991; Pietz et al. 1995; 68 females at Erskine). After marking, we located birds twice daily between 06:00 and 13:00 (Gloutney et al. 1993) using vehicle-mounted, null-array antenna systems and triangulation. Nesting attempts were suspected when triangulation placed a female in the same location for 5 consecutive mornings. We randomly allocated a subsample of all nesting attempts we encountered between 6 May and 19 June to either a control or an experimental group.

In the control group, nests were located and monitored only via telemetry; females were not flushed and nests were not visited while active. To estimate the location of control group nests we used hand-held antennas to take multiple bearings $(\leq 5)$ around the probable nest site. The number of bearings and the distance away from the nest from which these bearings were taken varied with the complexity of the habitat type. For example, in very simple habitat configurations such as a small, isolated patch of nesting cover surrounded by sparse vegetation not suitable for nesting, we remained quite far (e.g. $100-150 \mathrm{~m}$ ) from the nest and took only a few bearings. We aligned bearings with natural land features and/or small pieces of vinyl flagging and drew a detailed map of the estimated nest location to assist in relocating the nest when it was no longer active. Nesting site characteristics (habitat and vegetation type) were assigned to each nest from a distance. After a female Mallard was believed to be nesting, she was located via telemetry at least once each morning to monitor the status of the nest. If she was absent from the nest, a second location was obtained later the same day. If two consecutive telemetry readings indicated that the female was not in the area of the nest, we immediately searched for the nest, recorded nest-site vegetation characteristics, and determined the nest's fate (Klett et al. 1986).

In the experimental group, we visited the suspected nest site location and flushed the bird after triangulation placed her in the same location for five consecutive days. For each nest, we recorded vegetation characteristics around the nest site, number of eggs, and incubation stage (Weller 1956). We assumed a laying interval of one egg per day. Nest status was then monitored remotely using telemetry, and only when the female was absent for two consecutive telemetry locations was the nest visited again to determine its fate. Nest fate was considered abandoned due to inves- tigator activity when the stage of nesting (number of eggs or stage of incubation) did not change between nest visits (Klett et al. 1986) and subsequent telemetry locations indicated that the female was still alive but had failed to return to the nest after we had flushed her.

Because the study was a part of the PHJV assessment program, where one of the main objectives was to determine waterfowl nesting habitat preferences, we risked misclassifying control-group females as nesting when they were not. To minimize this risk to our overall study objectives, we excluded from both groups those nesting attempts where nests were located $<30 \mathrm{~m}$ from wetlands with standing water.

Vegetation characteristics around the nest site were recorded at two different scales. The habitat within a 2-m radius around the nest was recorded as: (1) grassland, (2) hayland, (3) planted cover, (4) cropland, (5) woodland, (6) shrubland, or (7) wetland (Emery et al. 2005). These classifications were applied to any patch of habitat $\geq 10 \mathrm{~m}$ across in its narrowest dimension. Nest site vegetation within a 0.5 -m radius of the nest bowl was characterized as one or more of the following types: (0) unvegetated, (1) annual crop, (2) upland graminoids-native, (3) upland graminoidsintroduced, (4) upland forbs, (5) low shrubs $(<1 \mathrm{~m})$, (6) tall shrubs $(1-6 \mathrm{~m}),(7)$ trees, (8) short emergent hydrophytes $(<0.5 \mathrm{~m})$, and (9) medium/tall hydrophytes $(>0.5 \mathrm{~m})$.

\section{Data Analysis}

To provide adequate sample sizes for analyses, data were pooled across habitats, study areas, and transmitter types. A chi-square test (PROC FREQ; SAS Institute 1997) was used to determine if there was a difference in the probability of hatching at least one egg (successful nest) between females that were flushed and those that were not. To test for investigator effects other than nest abandonment (i.e., predation), we removed those nests in the experimental group where investigators caused abandonment (Klett et al. 1986) and used Johnson's (1979) modification to the Mayfield method (Mayfield 1961, 1975) to estimate daily survival rates and hatching rates for the two groups. To detect differences in hatching rates, daily survival rates, weighted by exposure days, were used in a least-squares linear model (PROC GLM; SAS Institute 1997; Greenwood et al. 1995). To test for potential negative effects of radio-transmitters we compared clutch size and weighted daily survival rates between experimental nests and nests of non-radioed females found by systematic nest searches (Klett et al. 1986). We set decision levels at $\alpha=0.05$. Our research was reviewed and approved (protocol 19920007) by the University of Saskatchewan Committee on Animal Care and Supply.

\section{Results}

We located 137 nests (64 control; 73 experimental). Experimental nests had a mean age when found of 5.8 days $(\mathrm{SD}=3.0)$. Fifty-nine of the $64(92 \%)$ con- 
trol nests were physically located after they were no longer active. Because their success or failure could not be determined and habitat class and vegetation type could not be verified, the five control nests not located were excluded from further analyses. Differences in hatching rates between nests where the female was flushed (19.2\%; experimental) and those where she was not flushed $(27.5 \%$; control) approached significance $\left(\chi^{2}=2.952,1 \mathrm{df}, P=0.086\right)$. When 22 nests (30.1\% of experimental nests) that were abandoned due to investigator activity were removed, hatching rates did not differ between the two groups $\left(\chi^{2}=0.294\right.$, $1 \mathrm{df}, P=0.588$ ). Mayfield estimates (Klett et al. 1986) of hatching rates for experimental and control groups were $19.9 \%(95 \% \mathrm{CI}=11.8-33.4 \%)$ and $20.8 \%$ $(95 \%$ CI $=12.8-33.8 \%)$, respectively. Weighted daily survival rates of experimental $(0.9537)$ and control nests $(0.9549)$ did not differ $(F=0.001,1,5 \mathrm{df}$, $P=0.977)$. Nest loss due to predation occurred on average 10.1 days $(\mathrm{SD}=7.8, \mathrm{n}=34)$ and 9.1 days ( $\mathrm{SD}=6.7, \mathrm{n}=35$ ) following the date the nest was found or marked for experimental and control nests, respectively, and did not differ ( $t$-test, $t=0.57, \mathrm{df}=67$, $P=0.568$ ). Weighted daily survival rates between experimental nests and nests of non-radioed females (0.9536, $\mathrm{n}=44$ nests) did not differ $(F=0.0002,1,5$ df, $P=0.990)$. Mean clutch size between the two groups (8.8 eggs, $\mathrm{SD}=1.5, \mathrm{n}=32$ for experimental nests; 9.3 eggs, $\mathrm{SD}=1.1, \mathrm{n}=34$ for nests of nonradioed females) approached significance ( $t$-test, $t=$ $1.71, \mathrm{df}=64, \mathrm{p}=0.093$ ). Using radio-telemetry alone, we correctly estimated the habitat class for 55 of 59 (93\%) control nests. Nest site vegetation was correctly estimated for 33 of $59(56 \%)$ control nests.

\section{Discussion}

Low nesting success among prairie waterfowl (see Beauchamp et al. 1996), and particularly low nesting success among laying-stage nests (Miller and Johnson 1978), often necessitate locating nests early in laying if certain reproductive data are to be collected. But protocols requiring female Mallards to be flushed from their nests early in laying increase the likelihood of nest abandonment. Our investigator-caused abandonment rate of $30.1 \%$ was high and similar to the $24.3 \%$ investigator-caused abandonment rate for radio-marked Mallards encountered during the first year (1993) of our study. Livezey (1980) reported an investigator-caused abandonment rate of $6 \%$ with most abandonment occurring among nests found prior to the fourth day of laying. All investigator-caused nest abandonment $(n=22)$ in our study occurred the day the nest was first visited. Nests had a mean age at abandonment of 4.2 days $(\mathrm{SD}=1.8)$. While younger-age nests are more prone to abandonment (Ducks Unlimited Canada, Institute for Wetland and Waterfowl Research, unpublished data), other, unknown factors also probably influence abandonment, such as an individual female's tolerance to disturbance. We suspect radio-transmitters had minimal impact on the likelihood that females would abandon their nests following disturbance, but cannot verify this. Weighted daily survival rates did not differ between experimental nests and nests of non-radioed females $(P=0.990)$. However, differences in mean clutch size approached significance $(P=0.093)$. We were unable to compare investigator-induced abandonment rates between experimental nests and nests of non-radioed females because in a traditional rotational nest-searching scheme (see Klett et al. 1986), where nests are monitored at intervals of 7-10 days, the number of nests that are abandoned (either due to investigator disturbance or other factors) may be under-estimated because predators may destroy the nest before the next visit.

In contrast to the high investigator-related abandonment rates that we observed, only 6 (3 experimental, 3 control; 5.5\%) nests were abandoned for reasons other than investigator disturbance. The mean age of abandonment for these nests was 12.5 days $(\mathrm{SD}=6.2)$. Some of the highest reported incidences of natural abandonment were recorded by Duebbert et al. (1983) who found that Mallards nesting at high densities on an island abandoned $19 \%, 16 \%$ and $8 \%$ of their nests during the three years of their study. Because they did not visit the island during the nesting season, they concluded that inter- and intra-specific interactions, not investigator activity, were the major causes of abandonment (Duebbert et al. 1983).

When nests where investigator disturbance caused abandonment were removed from analysis, there was no difference in hatching rates or weighted daily survival rates between experimental and control nests. The temporal pattern of nest loss also did not differ among groups. It would appear then, that flushing a female Mallard and visiting the nest once did not increase the likelihood of predation. Thirty-four of 51 (66.7\%) experimental nests and 37 of $59(62.7 \%)$ control nests were destroyed by predators. Gotmark (1992) found a decrease in hatching rates attributable to investigator activity in $18 \%$ of published accounts where mammals were the dominant predators. In contrast, when avian predators dominated the egg-eating predator community, investigator disturbance led to increased predation of eggs (Gotmark 1992). Both avian and mammalian predators were common on our study sites (Ducks Unlimited Canada, Institute for Wetland and Waterfowl Research, unpublished data), yet we did not see increased predation resulting from investigators visiting nests once.

Investigator activity during early egg-laying appears to impact Mallard hatching rates through a high rate of nest abandonment. Although most modern waterfowl studies account for nests for which the investigator caused abandonment when estimating hatching rates (Klett et al. 1986), investigator-caused abandonment may lead to increased renesting and, subsequently, biased estimates of other reproductive parameters. 
For example, re-nesting birds usually produce smaller clutches (Rohwer 1992). Also, late-hatched ducklings may have lower survival and recruitment rates (Dzus and Clark 1998; Dawson and Clark 2000; Anderson et al. 2001; Blums et al. 2002; and see Rohwer 1992 for review of reproductive patterns). Causing birds to abandon their nests and, when re-nesting, select a new nest site also may bias estimates of habitat use and, if the new nest site has a different vulnerability to predation than the original nest, hatching rates. Although investigator-induced abandonment rates in a traditional rotational nest-searching scheme (Klett et al. 1986) typically would not approach the rates found in this study because most of our nests were found early in laying, the extent to which traditional nest search studies under-estimate abandonment rates should be investigated further. Radio-telemetry should provide a useful tool for that investigation.

Using radio-telemetry, we were able to collect accurate nesting information without disturbing the birds or visiting the nests until after the nests were no longer active. We were able to locate over $90 \%$ of the nests after they had hatched, were destroyed, or were abandoned by the female. Even if it had not been possible to locate such a high percentage of nests, we have demonstrated that it is possible to classify habitats with a high degree of accuracy using just telemetry. Not surprisingly, however, as the resolution of the habitat information became finer (i.e., nest site vegetation) our success rate declined. Nevertheless, radio-telemetry appears to provide a way to collect nesting data for waterfowl during the early egg-laying stage while avoiding the possibility of biasing data through increased abandonment rates.

Study results led to protocol change for the remaining years (1995 - 2000) of the PHJV assessment program. We estimated nest locations via triangulation and physically located nests later when females were absent from the nest areas. Investigator-induced abandonment due to accidental flushes during nest-marking averaged only $3.9 \%$ for the 22 study areas investigated during this period.

\section{Acknowledgments}

We gratefully acknowledge the cooperation of the Belmont, Davis and Erskine landowners for granting us access to their land. C. Archambault, B. Boldaun, D. Brooker, S. Cronin, F. DeZeeuw, V. Fairman, M. Francis, K. Hento, N. Herbert, P. Johnston, T. Krolikowski, D. Kuhn, G. Lacroix, C. Lamey, S. Leach, D. Marsh, K. Mott, A. Mullie, B. Parkin, K. Pilgrim, M. Post, K. Rattray, F. Rice, T. Sallows, D. Shaw, R. Terwilliger, P. Thorpe, J. Trevor, P. Varney, A. Viveiros, J. Walker and C. Wilke helped greatly with data collection. M. Barr, B. Calverley, K. Eskowich, A. Hak, M. Kornder, I. McFarlane, K. Remple, A. Richard, K. Schmitt and B. Thompson provided additional help during decoy trapping and we express our thanks. Ducks Unlimited staff from Manitoba, Saskatchewan, and Alberta provided invaluable support during site selection and landowner contacts. We thank R. R. Cox, A. J. Erskine, and three anonymous reviewers for providing helpful comments on earlier drafts of this manuscript. Financial support for this study was provided by Ducks Unlimited Canada, Ducks Unlimited Inc., the Canadian Wildlife Service, the National Fish and Wildlife Foundation, and the North American Wetlands Conservation Council through the Institute for Wetland and Waterfowl Research.

\section{Literature Cited}

Anderson, M. G., M. S. Lindberg, and R. B. Emery. 2001. Probability of survival and breeding for juvenile female canvasbacks. Journal of Wildlife Management 65: 385-397.

Balat, F. 1969. Influence of repeated disturbance on the breeding success in the mallard Anas platyrhynchos. Linn. Zoologicke Listy 18: 247-252.

Beauchamp, W. D., R. R. Koford, T. D. Nudds, R. G. Clark, and D. H. Johnson. 1996. Long-term declines in nest success of prairie ducks. Journal of Wildlife Management 60: 247-257.

Bellrose, F. C. 1980. Ducks, geese and swans of North America. $3^{\text {rd }}$ edition. Stackpole Books, Harrisburg, Pennsylvania. 540 pages.

Bennett, L. J. 1938. The blue-winged teal: its ecology and management. Collegiate Press, Ames, Iowa. 144 pages.

Blums, P., R. G. Clark, and A. Mednis. 2002. Patterns of reproductive effort and success in birds: path analyses of long-term data from European ducks. Journal of Animal Ecology 71: 280-295.

Butler, M. A., and J. J. Rotella. 1998. Validity of using artificial nests to assess duck-nest success. Journal of Wildlife Management 62: 163-171.

Dawson, R. D., and R. G. Clark. 2000. Effects of hatching date and egg size on growth, recruitment, and adult size of Lesser Scaup. Condor 102: 930-935.

Duebbert, H. J., J. T. Lokemoen, and D. E. Sharp. 1983. Concentrated nesting of Mallards and Gadwalls on Miller Lake Island, North Dakota. Journal of Wildlife Management 47: 729-740.

Dzus, E. H., and R. G. Clark. 1998. Brood survival and recruitment of Mallards in relation to wetland density and hatching date. Auk 115: 311-318.

Earl, J. P. 1950. Production of Mallards on irrigated land in the Sacramento Valley, California. Journal of Wildlife Management 14: 332-342.

Emery, R. B., D. W. Howerter, L. M. Armstrong, M. G. Anderson, J. H. Devries, and B. L. Joynt. 2005. Seasonal variation in waterfowl nesting success and its relation to cover management in the Canadian Prairies. Journal of Wildlife Management 69: 1181-1193.

Gloutney, M. L., R. G. Clark, A. D. Afton, and G. J. Huff. 1993. Timing of nest searches for upland nesting waterfowl. Journal of Wildlife Management 57: 589-601.

Gotmark, F. 1992. The effects of investigator disturbance on nesting birds. Current Ornithology 9: 63-104.

Gotmark, F., and M. Ahlund. 1984. Do field observers attract nest predators and influence nesting success of Common Eiders? Journal of Wildlife Management 48: 381-387. 
Gotmark, F., R. Neergaard, and M. Ahlund. 1990. Predation of artificial and real Arctic Loon nests in Sweden. Journal of Wildlife Management 54: 429-432.

Gottfried B. M., and C. F. Thompson. 1978. Experimental analysis of nest predation in an old-field habitat. Auk 95: 304-312.

Greenwood, R. J., A. B. Sargeant, D. H. Johnson, L. M. Cowardin, and T. L. Shaffer. 1995. Factors associated with duck nest success in the prairie pothole region of Canada. Wildlife Monographs 128. 57 pages.

Hammond, M. C., and W. R. Forward. 1956. Experiments on causes of duck nest predation. Journal of Wildlife Management 20: 243-247.

Hendricks, P. and D. L. Reinking. 1994. Investigator visitation and predation rates on bird nests in burned and unburned tallgrass prairie in Oklahoma: an experimental study. Southwestern Naturalist 39: 196-200.

Johnson, D. H. 1979. Estimating nest success: the Mayfield method and an alternative. Auk 96: 651-661.

Klett, A. T., H. F. Duebbert, C. A. Faanes, and K. F. Higgins. 1986. Techniques for studying nest success of ducks in upland habitats in the prairie pothole region. United States Fish and Wildlife Service Resource Publication 158. 24 pages.

Livezey, B. C. 1980. Effects of selected observer-related factors on fates of duck nests. Wildlife Society Bulletin 8: 123-128.

Low, J. B. 1940. Production of the Redhead (Nyroca americana) in Iowa. Wilson Bulletin 52: 153-164.

MacIvor, L. H., S. M. Melvin, and C. R. Griffin. 1990. Effects of research activity on Piping Plover nest predation. Journal of Wildlife Management 54: 443-447.

Mauser, D. M., and R. L. Jarvis. 1991. Attaching radio transmitters to 1-day-old Mallard ducklings. Journal of Wildlife Management 55: 488-491.

Mayfield, H. 1961. Nesting success calculated from exposure. Wilson Bulletin 73: 255-291

Mayfield, H. 1975. Suggestions for calculating nest success. Wilson Bulletin 87: 456-466.

Miller, H. W., and D. H. Johnson. 1978. Interpreting the results of nesting studies. Journal of Wildlife Management 42: 471-476.

Olsen, G. H., J. F. Dein, G. M. Haramis, and D. G. Jorde. 1992. Implanting radio transmitters in wintering canvasbacks. Journal of Wildlife Management 56:325-328.
Olson, R., and F. C. Rohwer. 1998. Effects of human disturbance on success of artificial duck nests. Journal of Wildlife Management 62: 1142-1146.

Pietz, P. J., D. A. Brandt, G. L. Krapu, and D. A. Buhl. 1995. Modified transmitter method for adult ducks. Journal of Field Ornithology 66: 408-417.

Poston, B., D. M. Ealey, P. S. Taylor, and G. B. McKeating. 1990. Priority migratory bird habitats of Canada's prairie provinces. Special Report, Canadian Wildlife Service and Environment Canada. 107 pages.

Reed, A. 1975. Reproductive output of Black Ducks in the St. Lawrence estuary. Journal of Wildlife Management 39: 243-255.

Ringelman, J. K. 1990. Decoy traps for ducks. United States Fish and Wildlife Service, Fish and Wildlife Leaflet 13. 2.10 .

Rohwer, F. C. 1992. The evolution of reproductive patterns in waterfowl. Chapter 15, Pages 486-539 in The ecology and management of breeding waterfowl. Edited by B. D. J. Batt, A. D. Afton, M. G. Anderson, C. D. Ankney, D. H. Johnson, J. A. Kadlec, and G. L. Krapu. University of Minnesota Press, Minneapolis, Minnesota. 635 pages.

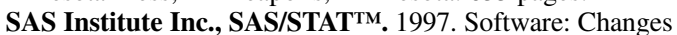
and Enhancements through Release 6.12. Cary, North Carolina: SAS Institute Inc. 1167 pages.

Sedinger, J. S. 1990. Effects of visiting Black Brant nests on egg and nest survival. Journal of Wildlife Management 54: 437-443.

Sharp, D. E., and J. T. Lokemoen. 1987. A decoy trap for breeding season Mallards in North Dakota. Journal of Wildlife Management 51: 711-715.

Sullivan B. D., and J. J. Dinsmore. 1990. Factors affecting egg predation by American crows. Journal of Wildlife Management 54: 433-437.

Vacca, M. M., and C. M. Handel. 1988. Factors influencing predation associated with visits to artificial goose nests. Journal of Field Ornithology 59: 215-223.

Weller, M. W. 1956. A simple field candler for waterfowl eggs. Journal of Wildlife Management 20: 111-113.

Received 3 August 2004

Accepted 4 November 2005 